\title{
Factors associated with health- related quality of life for adults with stroke sequelae
}

\author{
Karla Simone dos Santos Oliveira Fróes' ${ }^{1}$ Maria Teresa Moreno Valdés², \\ Daniel de Paula Lima e Oliveira Lopes ${ }^{3}$, Cruiff Emerson Pinto da Silva ${ }^{4}$
}

\begin{abstract}
Objective: To assess health-related quality of life (HROOL) among adults with stroke sequelae and to identify the factors that influenced the domains of HROoL. Method: The subjects were adults with stroke who were admitted to a rehabilitation program between March and August 2008. They were investigated using the following instruments: Medical Outcomes 36-Item Short-Form Health Survey (SF-36), Functional Independence Measure (FIM) and Beck Depression Inventory (BDI). Sixty-four adults of mean age 58.8 years were evaluated. Results: The individuals who had had their injuries for longer times and who were more independent and younger had better HROoL regarding physical functioning. Social participation was associated with better HRQoL, and there was a difference between groups with and without depressive symptoms. Conclusion: HRQoL was compromised primarily with regard to functional characteristics. Moreover, the presence of depressive symptoms contributed towards a decline in HRQoL. Rehabilitation needs to focus on improving functionality and social participation, which may stimulate reductions in depressive symptoms and improvement of HRQOL.
\end{abstract}

Key words: stroke, quality of life, depression, rehabilitation.

Fatores associados à qualidade de vida relacionada à saúde de adultos com sequelas de AVC

\section{RESUMO}

Objetivo: Avaliar a qualidade de vida relacionada à saúde (QVRS) de adultos com sequelas de acidente vascular cerebral (AVC) e identificar os fatores que influenciam os domínios da QVRS. Método: Adultos com AVC admitidos para programa de reabilitação de março a agosto de 2008, investigados com os seguintes instrumentos: SF-36, Medida de Independência Funcional e Inventário de Depressão de Beck. Foram estudados 64 adultos, média de idade de 58,8 anos. Resultados: Os indivíduos com maior tempo de lesão, mais independentes e jovens tiveram melhor OVRS na capacidade funcional. Participação social foi associada com melhor QVRS, e houve diferença entre os grupos com e sem sintomas depressivos. Conclusão: QVRS foi comprometida principalmente em seus aspectos funcionais. Por outro lado, a presença de sintomas depressivos contribuiu para a piora da QVRS. A reabilitação deve buscar a melhora da funcionalidade/ participação social, o que pode contribuir na redução de sintomas depressivos e a melhora da QVRS.

\section{Correspondence}

Karla Simone dos Santos Oliveira Fróes Neurorehabilitation Department Sarah Hospital

Av. Pres. Juscelino Kubitscheck 4500 60861-630 Fortaleza CE - Brasil E-mail: karlasimones@yahoo.com.br

Received 27 July 2010

Received in final form 9 December 2010 Accepted 17 December 2010
Palavras-chave: acidente vascular cerebral, qualidade de vida, depressão, reabilitação.

SARAH Network of Rehabilitation Hospitals, For taleza CE, Brazil

${ }^{1} \mathrm{MSc}$ in Public Health from the University of Fortaleza (UNIFOR), Brazil. Physiotherapist, Sarah Network of Rehabilitation Hospitals, Fortaleza CE, Brazil; ${ }^{2} \mathrm{PhD}$ in Psychological Science from the Central University of Las Villas (UCLV), Cuba. Psychologist and Researcher in Tecnalia Research \& Innovation, Spain; ${ }^{3} \mathrm{PhD}$ in Psychological Science from the University of São Paulo (USP), São Paulo SP, Brazil. Psychologist, Sarah Network of Rehabilitation Hospitals, Fortaleza CE, Brazil. ${ }^{4} \mathrm{MSc}$ in Interdisciplinary Computational Modeling, Visconde de Cairu Foundation (CEPPEV), Brazil. Statistician, Sarah Network of Rehabilitation Hospitals, For taleza CE, Brazil. 
Health-related quality of life (HRQoL) has been increasingly used as an important measurement for assessing the impact of stroke among such patients ${ }^{1}$. The often-used neurological and functional scales have limitations with regard to picking up changes in patient health, especially among minimally compromised individuals $^{2,3}$. HRQoL not only focuses on deficits or compromised functioning, but also takes into consideration the fact that quality of life (QoL) is an inherent attribute of self-perception and is able to measure various aspects of patients' general health ${ }^{4}$.

Through assessing HRQoL, it is possible to detect problems of psychosocial functioning or poor adjustment to the ailment, even in patients with good functional recuperation. In stroke cases, for example, patients who are quite independent, according to a functional evaluation, may have limitations on returning to work, leisure activities or emotional adjustment ${ }^{5}$.

Studies have shown decreased HRQoL following stroke $^{6,7}$. Martins et al. ${ }^{6}$ assessed the impact of stroke on HRQoL nine months after patient discharge from hospital, and found low perception of this in several domains. In a one-year follow-up on Chinese patients, Kwok et al. ${ }^{7}$ observed that there were no changes in physical functioning, as measured on scales, but that there was a decrease in HRQoL and increase in depression. Depression is a condition that negatively influences HRQoL ${ }^{8,9}$. Carod-Artal et al. ${ }^{8}$ found that depression and the degree of functioning were the foremost predictors of HRQoL one year after stroke.

The purpose of this study was to assess HRQoL among adults with stroke sequelae and to analyze the sociodemographic, clinical and functional factors that influenced the different domains of HRQoL among these patients.

\section{METHOD}

This was a cross-sectional study conducted at one of the units of the Sarah Network of Rehabilitation Hospitals in the city of Fortaleza, Ceará, Brazil. The participants in the study were adults with a diagnosis of stroke who were admitted to a rehabilitation program between March 2008 and August 2008. Out of the total number of 213 patients admitted, 64 met the criteria for inclusion in the study and agreed to participate.

The inclusion criteria were: a diagnosis of stroke confirmed by computed tomography (CT) or magnetic resonance imaging (MRI); duration of injury greater than six months; and sufficient cognitive capacity to collaboration with the information-gathering for the study. The MiniMental State Examination (MMSE) was used to screen the subjects regarding the adequacy of their cognitive capacity to collaborate with the study ${ }^{10}$.
Patients with other stroke-associated neurological and orthopedic pathological conditions that influence functionality, such as traumatic brain injury (TBI), Parkinson's disease, spinal cord injury (SCI), polio and fractures were excluded from the study. The study was approved by the Research Ethics Committee of the Sarah Network of Rehabilitation Hospitals, and informed consent was obtained from all participants.

The Medical Outcomes 36-Item Short-Form Health Survey (SF-36) was applied to evaluate HRQoL. This is a generic HRQoL questionnaire comprising 36 items that are distributed among eight domains, namely: physical functioning (10 items), physical role (4 items), bodily pain (2 items), general health (5 items), vitality ( 4 items), social functioning (2 items), emotional role (3 items) and mental health (5 items). The adjusted final score can range from 0 to 100 , where 0 represents the worst overall health status perceived and 100 represents the best overall health status perceived. A score of less than 50 in each area means that the quality of life is below average $^{11-13}$.

To obtain the degree of functioning, the scores of the Functional Independence Measure (FIM) were used. The FIM assesses the degree of assistance required by the patient in order to perform motor and cognitive tasks of everyday life. It describes a set of 18 tasks that provide a record of performance attained, divided into the following components: self-care (eating, getting ready, bathing, getting dressed and using the toilet), sphincter control, transfers, locomotion, communication (comprehension and expression) and social integration (social interaction, problem solving and memory). Each task receives a score from 1 (total dependence) to 7 (total independence), and thus the final score can range from 18 to 126 points $^{14,15}$.

The Beck Depression Inventory (BDI) was applied to investigate the presence of depressive symptoms. The BDI is an instrument comprising 21 types of symptoms and attitudes, with intensities ranging from 0 to 3 , such that 0 represents the absence of depressive symptoms and 3 the presence of very intense symptoms ${ }^{16-18}$.

The three instruments were applied during the first week of hospitalization, together with a sociodemographic questionnaire to obtain the following information: age, gender, marital status, education level, income, whether the patient had health insurance, whether the patient underwent physical therapy prior to admission, whether the patient took part in any previous rehabilitation program and presence of an active social life.

Clinical information on the type of stroke, side of the brain affected, time elapsed since the injury, number of strokes and presence of risk factors and/or co-morbidities for stroke was collected from the electronic patient chart. 
The data were treated in a descriptive and inferential manner. The categorical variables were presented in terms of absolute values and percentages, and the numeric variables in terms of means and standard deviations. We applied the Student $t$ test and variance analysis (ANOVA) for independent samples, in order to compare the influence of the numerical covariables on the HRQoL domains. The Pearson correlation was used to determine the correlation between the HRQoL domains and the numerical variables of the study. In order to estimate differences between each of the HRQoL domains, adjusted for the confounding effect of several covariables, stepwise multivariate linear regression analysis was used. For all statistical tests, the significance level $\mathrm{p} \leq 0.05$ was used, and the SPSS v13 software was used.

\section{RESULTS}

The sociodemographic and clinical characteristics of the study population are described in Table 1 . The mean age was 58.8 years $( \pm 11.72)$, and the time that had elapsed since the injury was predominantly between two and six years (50\%). Half of the patients were male $(n=32)$; most of the patients presented complete or incomplete primary education (57.8\%); most were married (53.1\%); and most had a monthly income of up to one minimum Brazilian wage (40.6\%). The most prevalent risk factors and/or comorbidities were: hypertension (81.3\%), dyslipidemia (46.9\%) and diabetes (21.9\%). Among the types of stroke, the most predominant was ischemic stroke (65.6\%).

Out of the total of 64 adults, nine could not be investigated by means of the BDI due to clinical instability or the fact that the program was interrupted prior to completing the first week of hospitalization. The prevalence of depressive symptoms was $40 \%(n=22)$, and the predominant symptoms were of mild to moderate intensity (21.8\%) followed by symptoms of moderate to severe intensity (12.7\%). The average BDI score was 11.65.

Figure shows the behavior of the averages for the eight domains of the SF-36. It can be seen that the domains with below-average scores $(\leq 50)$ were physical functioning, physical role and emotional role.

\section{Factors associated with}

\section{health-related quality of life}

In identifying predictors for the HRQoL domains, the multivariate regression analysis showed that the time elapsed since the injury and functionality had a positive relationship with physical functioning, and that age had an inverse relationship. Thus, patients with longer duration of injury who were more independent and younger had better HRQoL in relation to the physical functioning domain (Table 2).
Table 1. Sociodemographic and clinical characteristics of the study population.

\begin{tabular}{|c|c|c|}
\hline & No. & $\%$ \\
\hline Mean age, years (SD) & $58.80(11.72)$ & \\
\hline Mean FIM score (SD) & $4.26(1.07)$ & \\
\hline Mean BDI score (SD) & $11.65(9.86)$ & \\
\hline \multicolumn{3}{|c|}{ Time elapsed since stroke, years } \\
\hline$<2$ & 6 & 9.4 \\
\hline 2 to 6 & 32 & 50.0 \\
\hline$>7$ & 26 & 40.7 \\
\hline \multicolumn{3}{|l|}{ Sex } \\
\hline Male & 32 & 50.0 \\
\hline Female & 32 & 50.0 \\
\hline \multicolumn{3}{|l|}{ School level } \\
\hline No schooling & 3 & 4.7 \\
\hline Elementary school & 37 & 57.8 \\
\hline High school & 18 & 28.1 \\
\hline Higher education & 6 & 9.4 \\
\hline \multicolumn{3}{|l|}{ Marital status } \\
\hline Married & 34 & 53.1 \\
\hline Single & 14 & 21.9 \\
\hline Widowed & 9 & 14.1 \\
\hline Divorced & 7 & 10.9 \\
\hline \multicolumn{3}{|l|}{ Stroke type } \\
\hline Hemorrhagic & 22 & 34.4 \\
\hline Ischemic & 42 & 65.6 \\
\hline \multicolumn{3}{|l|}{ Depressive symptoms } \\
\hline Absent & 33 & 60.0 \\
\hline Light to moderate & 12 & 21.8 \\
\hline Moderate to severe & 7 & 12.7 \\
\hline Severe & 3 & 5.5 \\
\hline
\end{tabular}

For the physical role domain, the time elapsed since the injury and cognitive FIM established a significantly positive relationship. In the domains of vitality, social role, emotional role and mental health, the variable that established a negative relationship with these domains was the BDI score.

Finally, the "time elapsed since injury" variable showed a positive relationship with the social role domain. The numerical variables did not present any significant relationship with the "general health" and "bodily pain" domains.

Certain sociodemographic and clinical factors established an association with the domains of the SF-36 in this study. An active social life was associated with better HRQoL for the domains of physical functioning, physical role, general health, vitality, emotional role and mental 
Table 2. Factors that influence the HRQoL domains (multivariate linear regression analysis).

\begin{tabular}{lcc}
\hline Patients $(\mathrm{n}=64)$ & $\mathbf{P}$ & Coefficient \\
\hline Physical functioning & $<0.01$ & 0.569 \\
FIM total & $<0.01$ & 0.342 \\
Time elapsed since stroke & $<0.05$ & -0.213 \\
Age & & \\
Physical role & $<0.01$ & 0.347 \\
$\quad$ FIM cognitive & $<0.01$ & 0.539 \\
Time elapsed since stroke & & \\
Vitality & $<0.01$ & -0.548 \\
BDI score & & \\
Social functioning & $<0.01$ & -0.391 \\
BDI score & $<0.05$ & 0.346 \\
Time elapsed since stroke & & \\
Emotional role & $<0.01$ & -0.423 \\
BDI score & & \\
Mental health & $<0.01$ & -0.517 \\
BDI score & &
\end{tabular}

health $(\mathrm{p} \leq 0.05)$. Females had worse HRQoL only in the domain of physical functioning $(\mathrm{p} \leq 0.05)$.

The presence of only one cerebrovascular ictus was a positive influence on HRQoL in relation to the physical role domain $(\mathrm{p} \leq 0.01)$. Ischemic stroke was associated with better HRQoL in the bodily pain domain ( $\mathrm{p} \leq 0.05)$.

There was a significant difference between the groups of patients with and without depressive symptoms in relation to HRQoL for most of the domains, except for physical functioning and physical role. Table 3 shows that individuals with depressive symptoms had below-average scores $(\leq 50)$ for all of the domains.

The presence or absence of risk factors/comorbidities was not generally associated with HRQoL. However, regarding diabetes, the diabetic patients had worse HRQoL for the domain of physical role $(p \leq 0.05)$.

There was no significant association between quality of life and education level, marital status, side of brain damage, whether or not patient had health insurance, whether or not patient had undergone physical therapy before admission, or whether or not patient had taken part in a previous rehabilitation program.

\section{DISCUSSION}

This study investigated HRQoL among adults with stroke sequelae and the factors associated with this. The HRQoL domains most affected were physical functioning and physical role. Lower functionality contributed towards lower HRQoL only in these two domains,
Table 3. Influence of depressive symptoms in the HRQoL domains.

\begin{tabular}{lccc}
\hline & \multicolumn{2}{c}{ Depressive symptoms } & \\
\cline { 2 - 3 } & No & Yes & p \\
\hline Physical functioning & 38.83 & 33.81 & 0.561 \\
Physical role & 19.70 & 15.91 & 0.635 \\
Bodily pain & 71.48 & 50.91 & $<0.050$ \\
General health & 71.40 & 44.03 & $<0.010$ \\
Vitality & 72.27 & 45.23 & $<0.010$ \\
Social functioning & 72.35 & 46.02 & $<0.010$ \\
Emotional role & 61.62 & 31.82 & $<0.050$ \\
Mental health & 69.70 & 44.42 & $<0.010$ \\
\hline
\end{tabular}

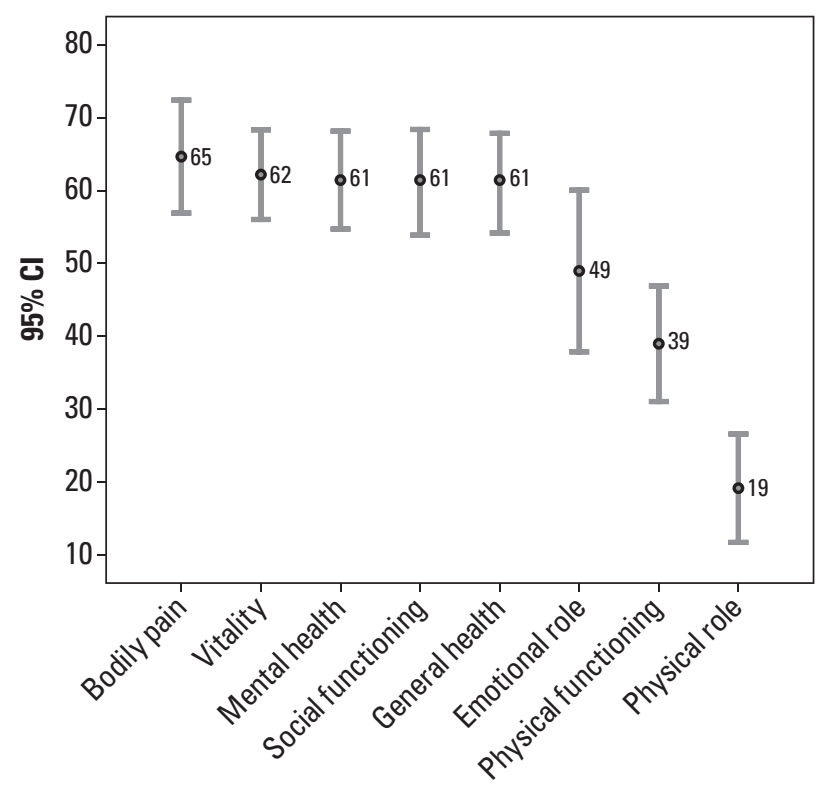

Figure. Description of the mean scores in the HRQoL domains.

while in the physical functioning domain, lower HRQoL also occurred in individuals with more recent injuries, higher ages, and who were more dependent. Thus, low functionality seemed to exert a major impact on people with stroke sequelae.

Moreover, when we divided the individuals into groups with and without depressive symptoms, those with depressive symptoms had below-average scores $(\leq 50)$ for all of the domains, thus suggesting that such symptoms have a high influence on HRQoL. Several studies have shown the influence of depression on HRQoL ${ }^{7-9,19}$.

However, there is controversy regarding the relationship between level of disability and HRQoL. Our study demonstrated that there was a relationship between greater disability and lower HRQoL only in the functional aspects of the SF-36 questionnaire. Some studies have also found greater correlation with the domains of 
physical functioning and physical role ${ }^{20,21}$. Olsson and Sunnerhagen ${ }^{21}$ found no differences among the eight domains of the SF-36, in comparison with motor and cognitive FIM. Similar results were obtained in the studies by Kong and Yang ${ }^{22}$. However, other studies have established a positive relationship between HRQoL and functionality for different domains ${ }^{8,9,23}$.

Perhaps one plausible explanation why this variation occurs among the studies is the fact that people with stroke sequelae may have their HRQoL affected, even without significant limitations in functionality. A followup study on stroke patients showed that low scores were maintained in several HRQoL domains, even in individuals with a higher degree of functional independence ${ }^{5}$.

The presence of an active social life appears to contribute towards better HRQoL, since such patients had better HRQoL for the domains of physical functioning, physical role, general health, vitality, emotional roles and mental health, compared with those without this indicator. Another study showed the influence of high social participation on better HRQoL ${ }^{9}$.

Other determinants of the patients' HRQoL could be identified. We found that female sex was associated with worse HRQoL in relation to physical functioning. This finding is consistent with results from other studies ${ }^{8,19,24}$. The presence of only one stroke (cerebrovascular ictus) contributed towards better HRQoL in the physical role domain. This finding may be justified when it is considered that more than one stroke tends to bring greater functional losses, which may contribute towards worse HRQoL.

As with other studies ${ }^{8,19}$, there was no significant association between quality of life and level of education, marital status, presence of comorbidities or side of the brain affected. What we found is that most studies on HRQoL, including our own study, have investigated a series of social, demographic, economic and clinical variables, but only a few studies have managed to establish some kind of relationship with these variables.

In relation to clinical characteristics, for example, Diaz-Tapia et al. ${ }^{23}$ showed that individuals with extensive cerebral infarctions had lower scores than did those with less extensive infarctions. Aprile et al. ${ }^{24}$ found that the physical component of HRQoL was more affected in patients with a low level of education, while for the mental component, there was more impairment in patients with high levels of education.

Another result from our study was that the patients presented moderate rates of depressive symptoms (40\%). Although these figures are rather variable among the studies, the results are similar to those found in the literature $\mathrm{e}^{25,26}$.

Generally, we can conclude that the HRQoL of adults admitted to a rehabilitation program was shown to be low only in the domains relating to functionality. However, the presence of depressive symptoms proved to be the aggravating factor that contributed most towards the lowering of HRQoL, because it affected several other domains.

We emphasize that further studies should be conducted, in searching for methodologies. These should include studies on the relationship between stroke and HRQoL, among the individuals who are most severely impaired from a cognitive viewpoint. This was not possible in the present study because of the inclusion criteria used in the sample. Similarly, studies using stroke-specific instruments will be able to identify other HRQoL domains affected in such patients, because such instruments have greater sensitivity towards the problems stemming from this condition.

It is clear that identifying depressive disorders and undertaking appropriate therapies for them must have a priority role in promoting HRQoL among people affected by stroke, and that this should be among the initial goals of rehabilitation programs.

\section{REFERENCES}

1. Gosman-Hedström G, Claesson L, Blomstrand C. Consequences of severity at stroke onset for health-related quality of life (HRQL) and informal care: a 1-year follow-up in elderly stroke survivors. Arch Gerontol Geriatr 2008;47:79-91.

2. Kissela B. The value of quality of life research in stroke. Stroke $2006 ; 37$ : 1958-1959.

3. Ronning OM, Stavem K. Determinants of change in quality of life from 1 to 6 months following acute stroke. Cerebrovasc Dis 2008;25:67-73.

4. Suenkeler $\mathrm{IH}$, Nowak M, Misselwitz B, et al. Timercourse of health-related quality of life as determined 3, 6 and 12 months after stroke. J Neurol 2002; 249:1160-1167.

5. Duncan PW, Samsa GP, Weinberger M, et al. Health status of individuals with mild stroke. Stroke 1997;28:740-745.

6. Martins T, Ribeiro JP, Garret C. Incapacidad y calidad de vida del paciente afectado por un accidente vascular cerebral: evaluación nueve meses después del alta hospitalaria. Rev Neurol 2006;42:655-659.

7. Kwok T, Lo RS, Wong E, Mok V, Kai-Sing W. Quality of life of stroke survivors: a 1-year follow-up study. Arch Phys Med Rehabil 2006;87:1177-1182.

8. Carod-Artal J, Egido JA, Gonzalez JL, Valera de Seijas E. Quality of life among stroke survivors evaluated 1 year after stroke: experience of a stroke unit. Stroke 2000;31:2995-3000.

9. Jönsson A, Lindgren I, Hallstrom B, Norrving B, Lindgren A. Determinants of quality of life in stroke survivors and their informal caregivers. Stroke 2005;36:803-808.

10. Bertolucci PHF, Brucki SMD, Campacci SR, Juliano Y. The mini-mental state examination in a general population: impact of educational status. Arq Neuropsiquiatr 1994;52:1-7

11. Ware JE, Kosinski M, Kelle SK. Physical and mental health sumary scale: a user's manual. Boston (MA): The Health Institute, New England Medical Center, 1994.

12. Anderson C, Laubscher S, Burns S. Validation of the short form 36 (SF36) health survey questionnaire among stroke patients. Stroke 1996;27: 1812-1816.

13. Ciconelli RM, Ferraz MB, Santos W, Meinão H, Quaresma MR. BrazilianPortuguese version of the SF-36. A reliable and valid quality of life outcome measure. Rev Bras Reumatol 1999;29:143-150.

14. Hamilton BB, Laughlin JA, Fiedler RC, Granger CV. Interrater reliability of the 7-level Functional Independence Measure (FIM). Scand J Rehabil Med 1994;26:115-119. 
15. Riberto M, Miyazaki MH, Jucá SSH, Sakamoto H, Pinto PPN, Battistella LR. Validation of the Brazilian version of Functional Independence Measure. Acta Fisiatr 2004;11:72-76.

16. Beck AT, Ward CH, Mendelsohn M, Mock J, Erbaugh J. An inventory for measuring depression. Arch Gen Psychiatry 1961;4:53-63.

17. Aben I, Verhey F, Lousberg L, Lodder J, Honig A, Psych MRC. Validity of the Beck Depression Inventory, Hospital Anxiety and Depression scale, SCL-90, and Hamilton Depression Rating Scale as screening instruments for depression in stroke patients. Psychosomatics 2002;48:386-393.

18. Gorenstein C, Andrade L. Validation of a Portuguese version of the Beck Depression Inventory and the State-Trait Anxiety Inventory in Brazilian subjects. Braz J Med Biol Res 1996;29:453-457.

19. Marco E, Duarte E, Santos JF, et al. Cuestionario de salud Short Form 36 en pacientes hemipléjicos a los 2 años postictus. Neurología 2006;21:348-356.

20. Patel MD, Tilling K, Lawrence E, Rudd AG, Wolfe CDA, McKevitt C. Relationships between long-term stroke disability, handicap and health-related quality of life. Age and Ageing 2006;35:273-279.
21. Olsson BG, Sunnerhagen KS. Functional and cognitive capacity and health-related quality of life 2 years after day hospital rehabilitation for stroke: a prospective study. J Stroke Cerebrovasc Dis 2007;16: 208-215.

22. Kong KH, Yang SY. Health-related quality of life among chronic stroke survivors attending a rehabilitation clinic. Singapore Med J 2006;47: 213-218.

23. Díaz-Tapia V, Gana J, Sobarzo M, Jaramillo-Muñoz A, Illanes-Díez S. Estudio sobre la calidad de vida en pacientes con accidente vascular cerebral isquémico. Rev Neurol 2008; 46: 652-655.

24. Aprile I, Piazzini DB, Bertolini C, et al. Predictive variables on disability and quality of life in stroke outpatients undergoing rehabilitation. Nerol Sci 2006;27:40-46.

25. Barker-Collo SL. Depression and anxiety 3 months poster stroke: prevalence e correlates. Arch Clin Neuropsychol 2007;22:519-531.

26. Caeiro L, Ferro JM, Santos CO, Figueira ML. Depression in acute stroke. J Psychiatry Neurosci 2006;31:377-383. 